This PDF is a selection from a published volume from the National Bureau of Economic Research

Volume Title: Governance, Regulation, and Privatization in the Asia-Pacific Region, NBER East Asia Seminar on Economics, Volume 12

Volume Author/Editor: Takatoshi Ito and Anne O. Krueger, editors

Volume Publisher: University of Chicago Press

Volume ISBN: 0-226-38679-1

Volume URL: http://www.nber.org/books/ito_04-1

Conference Date: June 28-30, 2001

Publication Date: January 2004

Title: What Has Been Achieved in the Japanese Telecommunications Industry since 1985 ?

Author: Tsuruhiko Nambu

URL: http://www.nber.org/chapters/c10196 


\section{What Has Been Achieved in the Japanese Telecommunications Industry since 1985 ?}

Tsuruhiko Nambu

In this paper I analyze the development of the Japanese telecommunications industry since 1985, when Nippon Telephone and Telegraph (NTT) public corporation - a natural monopoly - was privatized and competition was introduced into long-distance (i.e., interprefecture) markets. At the outset of the analysis I must stress the extreme importance of changes in mode of usage as well as technology over so short a period as fifteen years. This is crucial to the discussion below because there exist some economists who still live in the "medieval" age, when voice telephony was dominant and the market was structured consistent with this technology of the time, namely before 1985 . Voice telephony has a history of more than 100 years and the imprints of that age still are so strong as to blind some people to the scope of the new era that started in the early 1990s.

At the same time the nature of competition in telecommunications requires us to conduct a careful examination over the entire period. On the one hand, technological innovation has increased the choices of telecommunications services but it also has blurred the boundary of the market. We have now several telecom carriers and service providers in the local market. Does this mean that the local market has become competitive enough to abolish regulations upon incumbents? Because major telecom carriers are competing in borderless markets, the question arises: should the demarcation of the telecom market be based on a national boundary? Without in-depth empirical analysis we cannot answer either of these questions.

Tsuruhiko Nambu is professor of economics at Gakushuin University.

I am grateful to the comments by Il Chong Nam, Richard Snape, Takatoshi Ito, and Anne Krueger, and especially to Robert Graniere for his thorough reviewing of my paper. Remaining errors are all mine. 
From the viewpoint of competition policy, competition authorities like the Japan Fair Trade Commission must accumulate knowledge in the telecommunications industry. In the United States, the Federal Communications Commission (FCC) and the Department of Justice (DOJ) have a long history of regulating AT\&T and other telecom carriers on a daily basis or combating AT\&T in the court. Consequently they have enough resources and capabilities to deal with the new developments in the telecom industry. In Japan the public monopoly was not subject to regulation and antimonopoly laws until recently. It has only been during the last fifteen years that the government has regulated this industry. It must also be noted that the Japanese regulator is not an independent authority but rather an intraministerial bureau.

The government-business relationship plays an important role in the process of deregulating natural monopoly industries (see Nambu 1997a). The Japanese institutional traits will be the focus of this paper in order to make the last fifteen years of the Japanese telecom industry understandable.

\subsection{Introductory Perspective}

This introduction clarifies the basic structural changes in technology and demand that have occurred in the telecom industry relatively recently (in the last fifteen years) by dividing those years into three periods. This is necessary because of the many structural changes that have occurred during these years.

\subsubsection{Phase I: Up To the Early 1980s}

Although optical fiber technology had been commercially developed and was partly introduced, telephone networks were almost exclusively wired with copper technology. Voice traffic was carried over a copper loop and switched at the exchange. In this phase the most striking feature of the industry lay in the fact that telecom services are homogeneous. Of course, there existed an artificial boundary that was set by regulators between local and long-distance services. This boundary reflected a technological hierarchy that was intended to realize economies of scale and scope. Longdistance services are different from local services because they are supplied through a higher hierarchical switching network. But from the viewpoint of economics, they are identical goods except for the illusion that longdistance services used to be regarded as luxuries because they were priced higher than local service in order to realize a cross-subsidy from longdistance to local services. But not withstanding this fact the breakup of AT\&T was based on the conviction at that time that long-distance service had a different market structure than local service. In the days of Ma Bell, that is, the days prior to the AT\&T breakup, all telephone services were 
"costed out" on a "station-to-station" basis. However, it had long been thought that the long-distance services were actually "board-to-board" services.

When AT\&T was divested, general agreement existed that the longdistance (interstate) market was competitive as a result of technological innovations, whereas the local market was and should remain a natural monopoly. This dichotomy has plagued the dynamic development of the telecom industry in Japan as well as in the United States. Even though this dichotomy was accepted by the majority of economists in both countries, it should not have been treated as a doctrine. However, as a rule, once regulatory agencies accept a certain way of thinking, they usually stick to it until a visible and undeniable change has occurred.

13.1.2 Phase II: From the Middle of the 1980s to the Middle of the 1990s

Structural change came in several ways during this period.

\section{Wireless Technology}

Wireless technology is kind of an old technology in a sense that it was used widely in military and some business applications. The problems with this technology are the difficulty of handling wireless equipment and the volatility of communication. Once these difficulties are alleviated, it is obvious that wireless technology has an extreme advantage over wireline services. It is also true that wireless technology has often been utilized by telephone companies as an alternative to wireline technology when short-distance voice services are transmitted to the switches. Under the name of the "geodesic" network, a provocative scenario was presented wherein the telecom industry could be totally restructured by wireless technology and this industry could be contestable. ${ }^{1}$

\section{Cable Television}

Cable television (CATV) started as an auxiliary broadcasting service in a limited area where the terrestrial TV radio signal is very weak. Over time, it became apparent that this technology could be used in telecommunications as well. The competitive pressure that CATV exerts against wireline telephony depends on its penetration rate. In the United States, CATV is deemed to be competitive with telephony although the quality of CATV service providers is controversial. In Japan, CATV has not reached this stage. Though the history of CATV is rather short, it has been demonstrated that CATV can effectively compete with local telephone companies and provide broadband services as well.

1. The idea was first introduced by Peter W. Huber in a report to the Department of Justice, The Geodesic Network (Huber 1987). The second version was published in 1992 (Huber, Kellogg, and Thorne 1992). 


\section{Internet}

The development of the Internet as a popular data transmission vehicle has changed the telecommunications market as well. It took years for telephone businesspeople to be convinced that the Internet is a new communication device and to dismiss their old paradigm as a result. The difference between the Internet and telephony is especially remarkable at two points. First, routers replace switches but switches are designed to ensure perfect connection among subscribers. Second, Internet users prefer to be continuously connected without having to pick up a phone. These particularities of the Internet have imposed changes upon telephone companies and regulators but there have been noteworthy differences in the speed of compliance with these changes among countries. Although aware that they are challenged by these fundamental structural transformations, the telephone companies and their regulators have not been quick to change their view of the industry.

\subsubsection{Phase III: From the Middle of the 1990s to the Present}

Faced with revolutionary changes in the telecommunications industry, the legislators set out to initiate a new framework corresponding to the new economic reality. In 1996 the Federal Communications Act of 1934 was amended in the United States and was enacted for the purpose of realizing competition between long-distance carriers and regional Bell operating companies (RBOCs). In Japan the long dispute over the NTT managerial form was settled in 1999 and the reshaping of NTT was realized by creation of a holding company with the three subsidiaries, NTT East and West (which are local companies) and NTT communications (which is a longdistance and international company). However, these two reforms, both in the United States and in Japan, up to now appear not to be fruitful.

It has become clearer during this period that new entrants into the telecom industry found and employed a new strategy: namely, "politicizing" (gaming) entry conditions for the purpose of reducing entry costs and risks. New entrants learned that they could lower entry barriers by arguing to policymakers that incumbents are always trying to preclude entry. This is economically beneficial to the new entrants because they can reduce their entry costs if they do not need to invest in new facilities that might be sunk in the future. At the same time, regulators have learned that they can cater to the public by protecting entrants and quarrelling with incumbents. Their interests coincide to put pressures upon incumbents.

In the case of the United States, the focus of the disputes among regulators, entrants, and incumbents lies in the difficulty of fulfilling the checkpoints imposed on the RBOCs by the 1996 act. Once these checkpoints are fulfilled, the RBOCs can enter the long-distance markets. It is natural that 
long-distance carriers are fearful of competition from the RBOCs because they face a high probability of losing their customers.

The Tauzin-Dingell bill was discussed in the House of Representatives in the United States in 2001. This bill intends to give RBOCs the freedom to invest in broadband services on an inter-local access and transport area (inter-LATA) basis.

The Japanese government has begun to discuss the possible reshaping of NTT, which was reorganized in 1999.

\subsection{Historical Background}

\subsubsection{The Creation of a Public Monopoly}

The Japanese choice of industry structure after privatization in 1985 may be better understood by looking back on the origin of the system of telecommunications service provision established in 1957. After World War II, the Japanese government faced the problem of rebuilding an infrastructure that had been destroyed by the war. This infrastructure was required to support rapid renovation for economic development. There existed conflicting opinions as to how to structure the telecommunications service provider. Japan ultimately chose a public-corporation type of common carrier for telecom services. The public corporation was called Denden Kosha, or the Nippon Telegraph and Telephone public corporation, which was placed under the supervision of the Diet but independent of the regulatory oversight of the Ministry of Posts and Telecommunications (MPT).

The idea of Kosha was to create independence for the investment policy for telecommunications facilities. Denden Kosha succeeded in eliminating the backlog demand for subscription to the telephone network. This objective was accomplished around 1977 or 1978. During this developmental period the Denden Kosha served as a public monopoly with a bureaucratic administration that worked to provide telecommunications services to the public. On top of that, Denden Kosha's board members consisted of carrier bureaucrats who had moved from the Ministry of Communication that existed until 1949. It is often observed that bureaucrats do not initiate new business forms until they are absolutely certain that the old forms are not appropriate any longer. This type of behavior nourished the corporate culture of NTT and it was liable to complaints and criticism directed at its inflexible and slow response to changes in demand, especially from the business world.

Amid the global wave of deregulation in the United States and privatization in the United Kingdom, the Japanese government decided to privatize NTT in 1985. The initial institutional arrangements were as follows: 
1. NTT corporation replaced the public monopoly, Denden Kosha. NTT became a private company but was a special entity because more than 51 percent of its shares were held by the government. It also inherited a public obligation as "universal service."

2. Instead of the Public Telecommunications Law, the Telecommunications Business Law became the key determinant of the industrial structure of the telecom industry. Under this law, telecom service providers are classified into two categories, Type I and Type II. The former owns telecom facilities, whereas the latter rents them from Type I carriers.

3. The $\mathrm{MPT}^{2}$ was put in charge of regulating Type I and Type II carriers. In the day of the public monopoly, Denden Kosha was under the surveillance of the national Diet. At the time of Denden Kosha, regulation by the MPT was rather nominal. Therefore there did not exist any conflict between MPT and NTT. In fact, the Kosha system itself was created in order to encourage and respect the independence of Kosha.

\subsubsection{NTT versus MPT: Institutional Stalemate}

In this section I analyze the structural difficulty of decision making in Japan from the viewpoint of the Japanese regulatory scheme as compared to the regulatory schemes of the United States and the United Kingdom.

First, the Japanese regulatory scheme might be called a simply unified jurisdiction system, in the contrast to that of the United States, where several agencies are competing with each other (e.g., the FCC, the DOJ, state public-utility commissions, and the court in the case of telecommunications). Contrary to this decentralized system in the United States, there usually exists in Japan one ministry that is in charge of a certain industry or industries. In some cases, this type of centralization has been challenged by other ministries. The Ministry of International Trade and Industry, or MITI, used to challenge MPT because MITI regulated the computer industry. If MITI's challenge had been effective, the concentration of power in MPT would have been weakened. But up to now MPT has not faced a serious challenge. As a result, Japanese telecommunications regulation has been centralized in the hands of MPT.

The difference between a centralized and a decentralized regulatory system seems clear when we compare Japan and the United States. The comparison between Japan and the United Kingdom, however, raises a different problem. These two countries have a centralized bureaucracy in common, although in the case of the United Kingdom, the Office of Telecommunications (OFTEL) was newly created for regulating the telecommunications industry. The creation of telecommunications regulatory pol-

2. The name of MPT vanished during the recent restructuring of ministries, and MPT has become a regulatory agency in the Ministry of Public Management, Home Affairs, Posts, and Telecommunications. 
icy is in the hands of top executives who are appointed by the government, whereas Japan has a tightly integrated, hierarchical structure of bureaucrats. It is a good contrast that, unlike in Japan, political appointees in the United Kingdom are requested to articulate their own philosophy of regulatory policy.

Second, it is instructive to look at the business-government relationship in Japan as compared to that in the United Kingdom. In Japan, MPT was given jurisdiction over the telecommunications industry for the first time in 1985. NTT public corporation was privatized at that time, but it naturally inherited the bureaucracy created during the days of Kosha. Being ambitious to apply an industrial policy toward the telecommunications industry, MPT invited new entrants into the industry and tried to protect them from the dominance of NTT. The means of protection has been to place NTT under the strict regulation of MPT. As a result, conflicts between MPT and NTT have not been unusual. NTT, being an integrated bureaucracy, had accumulated a deep knowledge of the telecommunications industry and is still the most knowledgeable service provider. MPT was a latecomer that was lacking in industry-specific expertise when it was given the authority to regulate the telecom industry. But MPT took the approach of omnipotent regulator from the outset. As a result, Japan had two bureaucracies that claimed legitimacy.

In the United Kingdom the new regulatory agency, OFTEL, took a different approach toward British Telecom (BT). OFTEL adopted pricecap regulation, which is intended to give positive economic incentives to the incumbent firm. In addition to allowing flexible rate rebalancing by BT, OFTEL admitted one new competitor, Mercury. Price-cap regulation meant that BT did not face the same financial difficulty as NTT because it could rebalance its rates in a few years after privatization in 1984, although BT always claimed the existence of an access deficit. The policy goal of OFTEL had been announced clearly by the director general and the negotiation between OFTEL and BT did not include fatal conflicts such as there used to be in Japan. Sometimes OFTEL was criticized for being too indulgent to BT. This is in contrast to Japan, where MPT protected new entrants by hemming in or handcuffing NTT.

By comparing these cases we can tentatively conclude that "bad" business-government relationships, and conflicts and strains between regulators and the regulated firms, bring about a serious time delay in meeting the challenges of a change in environment. Consider especially the incredibly rapid change of telecommunications technologies. Slow decision making as a result of the regulatory scheme is the greatest obstacle to industrial development. Slow decision making is typically the case in Japan, especially with respect to the introduction of arrangements for new businesses. NTT's business was narrowly restricted to the domestic market, where new entrants were allowed to earn handsome profits from the continuing high 
prices inherited from the regulatory system. On the other hand, new entrants failed to exhibit innovative marketing to create new services. Next, the difficulties of the Japanese telecommunications industry brought on by a bad business-government relationship are examined.

\subsubsection{Dispute over Divestiture}

Before privatization of NTT, there was a discussion of the possibility of an NTT divestiture, à la the AT\&T breakup in 1984 in the United States. But no conclusion was reached and it was decided that the discussion would be resumed in 1990. At that time, MPT proposed the breakup of NTT based on a report issued by the Telecommunications Council. However, the Ministry of Finance, the Telecommunications Labor Union, and the politicians were against MPT's proposal and no conclusions were reached in 1990. During this second discussion the conflict between NTT and MPT became clearer. NTT refused the idea of divestiture, and MPT refused to abandon it. Although Denden Kosha was privatized, the two bureaucratic systems had reached a stalemate.

The Japanese stock market responded negatively to this situation and the NTT stock price dropped drastically. As a result, any further flotation on NTT stocks became impossible. This induced a huge capital loss for NTT stockholders and had an adverse influence upon the possible flotation of other public corporation stocks, such as the Japan Railways (or JRs; the Japan National Railway was privatized and reshaped into seven JRs). This kind of confrontation between the regulator and the regulated firm inevitably creates uncertainty about the future of the industry.

In 1995 the discussion on the possible divestiture of NTT was resumed, but again, no conclusion was reached. At this point in time, the structural change of the telecom industry appeared clearer. The U.S. government had proposed the National Information Infrastructure scheme to enhance the development of information technology. The National Information Infrastructure anticipated that a new industrial structure might be needed to capitalize on improvements in information technology. It has now become essential to determine how to structure the telecom industry consistent with potential of information technology. The most plausible scheme for facility-based competition in the local telephone market is based on the emergence of new information technologies.

The most likely facility-based entrants into the local market were the long-distance carriers. In 1996 the Federal Communications Law was enacted to break the old boundary between local and long-distance services.

The political situation in Japan at this time was about the same. There were only a few examples of competition in the local market. Tokyo Telecommunication Network Co., Inc. (TTNet), a subsidiary of the Tokyo Electric Power Company, entered the Tokyo area and Osaka MediaPort Corp. (OMC), a consortium of an electric power company and others, en- 
tered the Osaka market. But the geographic area covered by the entrants was very limited and accounted for almost nil.

The Japanese government needed to settle the old dispute over NTT's organizational form if it was to foster further competition. At last a compromise was worked out in 1999. A new holding company was created that allowed the old NTT's three divisions to become three separate subsidiaries of the new NTT Holding Company. However, this conclusion to the discussion of the breakup of the old NTT contains inherent contradictions.

\subsubsection{Rate Rebalancing and Access Charges}

In the United Kingdom, BT was allowed to rebalance its rates as part of the implementation of price-cap regulation, whereas in the United States a brand of new access-charge system was established as a condition of the AT\&T divestiture. But in Japan, neither rate rebalancing nor access charges were introduced (fig. 13.1).

This is mainly because NTT and MPT collided on the question of the local and network access deficits. NTT had provided estimates on the size of these deficits but MPT refused to accept them. MPT wanted a structural solution in the form of a structural separation, and to make the industry's cost structure visible to industry observers. NTT complied with MPT's wishes by changing its managerial structure into a long-distance business center and local telephony business centers. This structural division is based upon artificial and arbitrary allocation of the common costs of the whole company. If there had existed mutual confidence and trust between NTT and MPT, the NTT's deficit problem would have been solved earlier. But this was not the case. The delays associated with reaching an agreement have brought about serious economic distortions in the Japanese

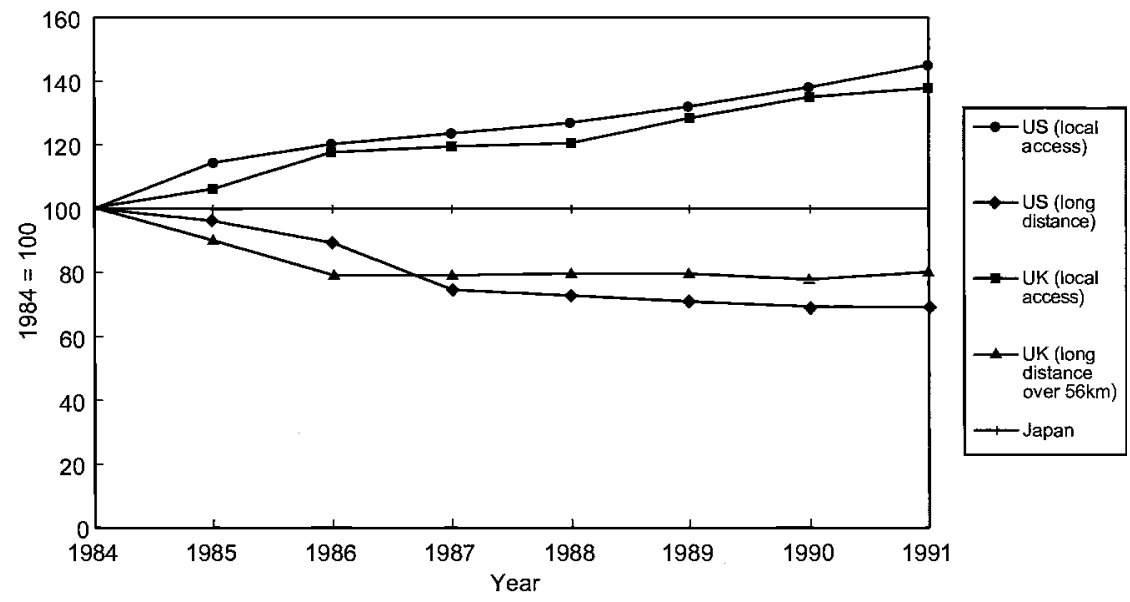

Fig. 13.1 Comparison of rate rebalancing: Japan, U.S., U.K. $(1984=100)$ 
telecommunications industry. Rate rebalancing is necessary to restore a signaling function of price that is not distorted by the cross-subsidy system of the monopoly era. On top of that, telecom technologies have been everchanging. If rates continue to be biased by artificial cross-subsidies, the new technology cannot find its suitable place in the market. Consequently the delay caused by the regulatory conflict has inflicted tremendous social cost to Japan from the viewpoint of income distribution as well as efficiency.

It was not until 1994 that an agreement on an access-charge payment was established. The new common carriers (NCCs), which are equal to the other common carriers (OCCs) in the United States, were required to pay about 20 billion yen in addition to the local rate that they already paid to NTT. This additional payment is approximately equal to, say, what NCCs used to be paid in the form subsidy from NTT subscribers. The imposition of a new access charge meant that hidden subsidy was removed. This had a negative impact upon the NCCs' profitability, which, in turn, influenced their investment strategy. If the access-charge arrangement had been realized earlier, then the NCCs' investment behavior might not have been affected so badly. The delay in the resolution of access-charge issues may have given the wrong signal to the NCCs, causing them to invest in lowdensity areas throughout the country.

\subsubsection{Punishing NTT Policy}

In the dynamic process of change from monopoly to competition, several structural amendments are necessary to abolish the old institutional restraints. The most basic regulatory framework is based upon a system of cross-subsidy between local and long-distance telephony. As usual, the local telephone rates are maintained at lower levels than their costs on the grounds that local telephone service could not be viable without subsidy.

In preparing for the introduction of competition in the long-distance market, it was deemed necessary in the United States and the United Kingdom to reshape this cross-subsidization mechanism. In contrast with them, Japan was a unique country where no discussion on issues such as access charges or rate rebalancing occurred. The Japanese government simply ordered the newborn NTT to continue to provide local as well as long-distance telephone service without changing its tariff structure. This would mean that new entrants into the long-distance market can earn extraordinary profits by charging slightly lower prices as compared to the NTT tariff. MPT officially admitted that this regulatory policy amounted to cream-skimming by the new entrants. NTT must suffer losses in the long-distance market while it continued to provide below-cost local service.

In Japan it was partly justified on the basis of apathy toward "monopoly" firms. NTT was, in the eyes of the government, an inefficient monop- 
oly and excessive resources were said to be built into the organization. As a result, it was argued, NTT could respond to the competition by reducing its extra costs. In other words, suffering is a necessity for the rebirth of NTT. This point of view is valid as far as there exist extra costs to be removed, but it is a "once-and-for-all" remedy because extra costs must disappear in the process of competition with newcomers. But the reality at that time was that there existed no apparent signal from the government concerning the time horizon of its policy, which resulted in the sharp and sustained decline of NTT's share price ever since the issue of the stock in 1985.

\subsection{Competition in the Long-Distance Market}

The three NCCs, Daini Denden Incorporated, Japan Telecom, and Teleway Japan, entered and began telephony service in 1987. They successfully competed with NTT because there existed a price differential between NTT and NCCs.

Figure 13.2 shows that the price of an NCC was about 15 to 20 percent lower than NTT's regulated rate. If NTT had been allowed to match the NCCs' price without delay, the advantage of the NCCs may not have been so great. But NTT was not allowed to do so and the price differential accounted for the NCCs' success. In the face of this outcome we must ask whether the NCCs' success was justifiable from the viewpoint of efficiency.

Under the Telecom Business Law, the number of competitors in the market was regulated by MPT pursuant to a supply-and-demand balancing clause. MPT allowed three NCCs to enter and cream-skim the longdistance market. Cream skimming was possible because NTT was not allowed to rebalance its rate or to impose access charges on these NCCs. At least two of three NCCs made huge profits since the early 1990s. Figure 13.3 shows the markup rate differences among carriers. From 1995, the markup of NCCs declined because of the introduction of an access charge and price reductions by NTT.

Another problem with the initial introduction of competition into Japan's long-distance market is a deep concern with dynamic efficiency. No one can know whether newcomers, once selected by MPT, are efficient challengers of NTT. Unlike in the United States, where the number of competitors in the long-distance market was not regulated by the FCC, Japan could not depend upon the usual entry and exit mechanisms to eventually sort out the efficient and inefficient firms. The Japanese style of regulation cannot guarantee the kind of efficiency that should be a trademark of a newly competitive industry.

The advantageous status of NCCs can be justified, in theory, as providing protection to an infant industry. But as is clearly discussed in the economics textbooks, the government cannot protect newcomers forever. 


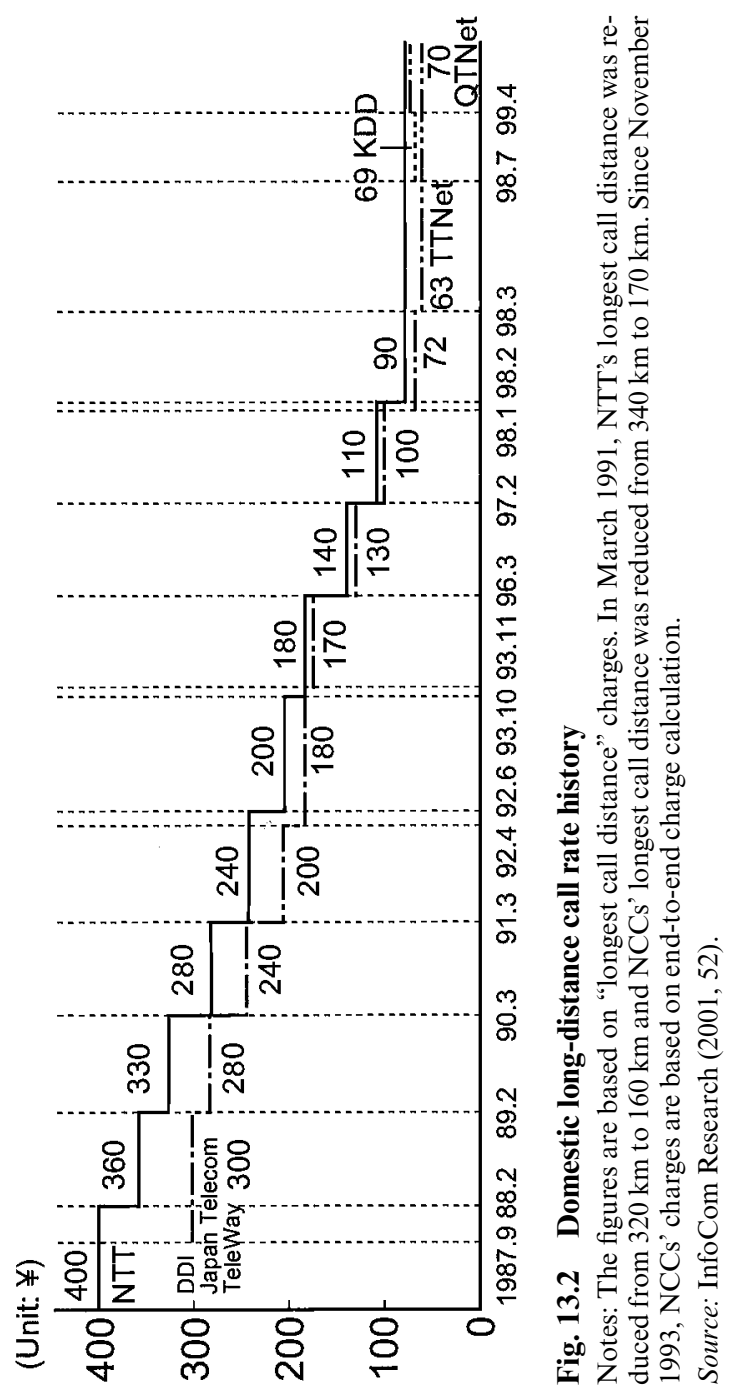




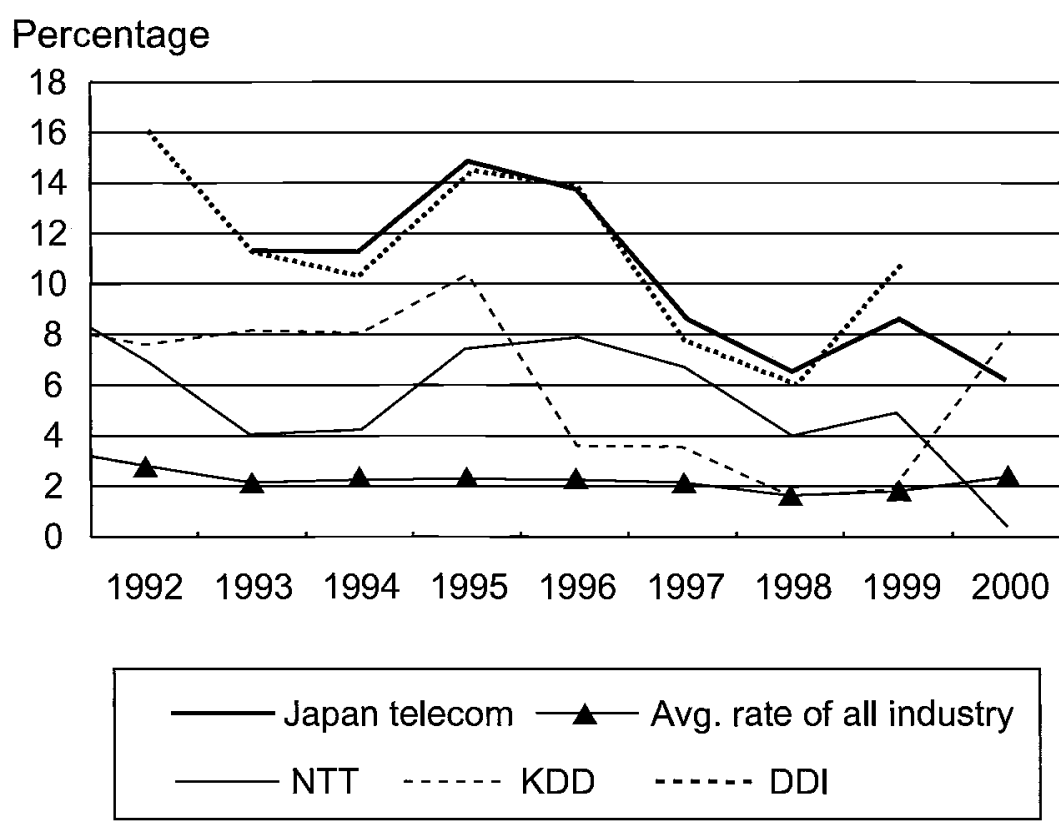

Fig. 13.3 Make-up rate of carriers

There must always exist some time limit (sunset) when protection comes to an end and is replaced by the free entry of other firms; otherwise, the wrong signals will be sent to the existing three firms. If MPT had sent a signal to the NCCs in the early stages that it would abandon their protection, the NCCs might not have misunderstood their position as permanent and might not have invested excessively to exploit quasi rent from protection (see fig. 13.4).

It is clear that the NCCs tried to exploit quasi rents in the 1990s. Because of their high profitability on the one hand and mutual competition on the other, they expanded their business areas throughout the country. However, there are diminishing returns when long-distance carriers increase the points of interface since the busiest business areas in Japan are concentrated in a limited number of large cities like Tokyo, Osaka, Nagoya, Fukuoka, and Sapporo. If the NCCs had given proper consideration to the possibility that they would lose their government protection, it is reasonable to conclude that their investment might have been restricted to certain areas. But they were sluggish to change their business policies even in the face of competition from discounters like AT\&T that are not Type I carriers.

With the development of price competition in the late 1990s, the three NCCs met financial difficulties in the long-distance market. This was 


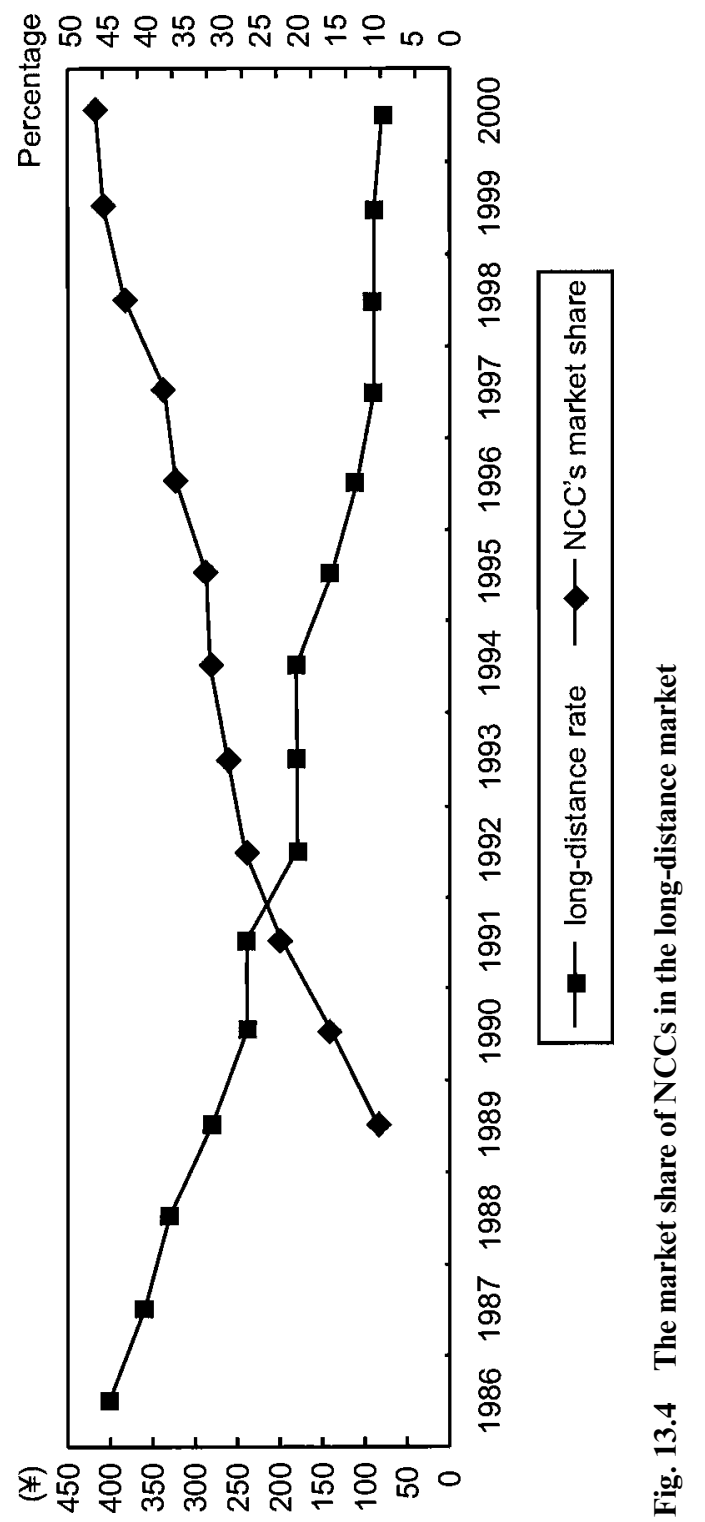


simply because voice telephony service is homogeneous and, as a result, product differentiation is impossible. This is a common phenomenon in any country. When long-distance rates are approaching their marginal costs, competition may well be ruinous, as was often seen in the past.

Their tenure was ended by the following events (summarized in fig. 13.5):

- Teleway Japan Inc. was established by the Toyota group. This company failed to expand its business nationwide and vanished in December 1998, merging with Kokusai Denshin Denwa Co., Ltd. (KDD).

- KDDI was created by the merger between Daini Denden Inc. (DDI) and KDD; Nippon Idou Tsushin Corp. (IDO) joined KDDI in October 2000.

- Japan Telecom (JT) was created by the Japan National Railways, and International Telecom Japan, Inc. (ITJ) was absorbed into JT in October 1998. Vodaphone owns 45 percent of the JT shares. TU-KA Cellular Tokyo, Inc. (mobile) phones joined Vodaphone in August 1998.

- TTNet is a subsidiary of Tokyo Electric Power Company. It succeeded in acquiring local telephone subscribers in the Tokyo area, and its turnover is nearly 200 billion yen.

Some remarks are possible based on the review of the NCCs' history.

The intent of the regulator to foster long-distance competition has failed in the following sense. The number of entrants had been limited to three. Nobody could know whether these firms were efficient challengers to NTT. Accordingly, Japan needed to introduce a mechanism to examine the efficiency of new entrants into the long-distance market. MPT could abolish entry regulations on the long-distance market, as was done in the United Kingdom in 1990. If entry had been liberalized in the early 1990s, the addition of new long-distance carriers could have been speeded up. The protectionism of MPT invited the efficiency loss.

The entry of NCCs may be regarded as a success in the sense that NTT's long-distance share dropped to almost 50 percent. Without entry pressure, NTT's dominance would have persisted. This argument is well taken, but there still is the question of whether NTT's lost market share was captured by the most efficient entrants. Without free entry, there is no guarantee that the most efficient new entrants absorbed NTT's market share. In fact, it is doubtful whether this kind of substitution happened in the Japanese longdistance market.

\subsection{Competition in the Local Market}

Although it was generally believed at the time of the codification of the Japanese Telecom Business Law that the local telephone market was a natural monopoly, new legislation allowed competitors into the local market immediately. The first entrants were electric utility companies that created 


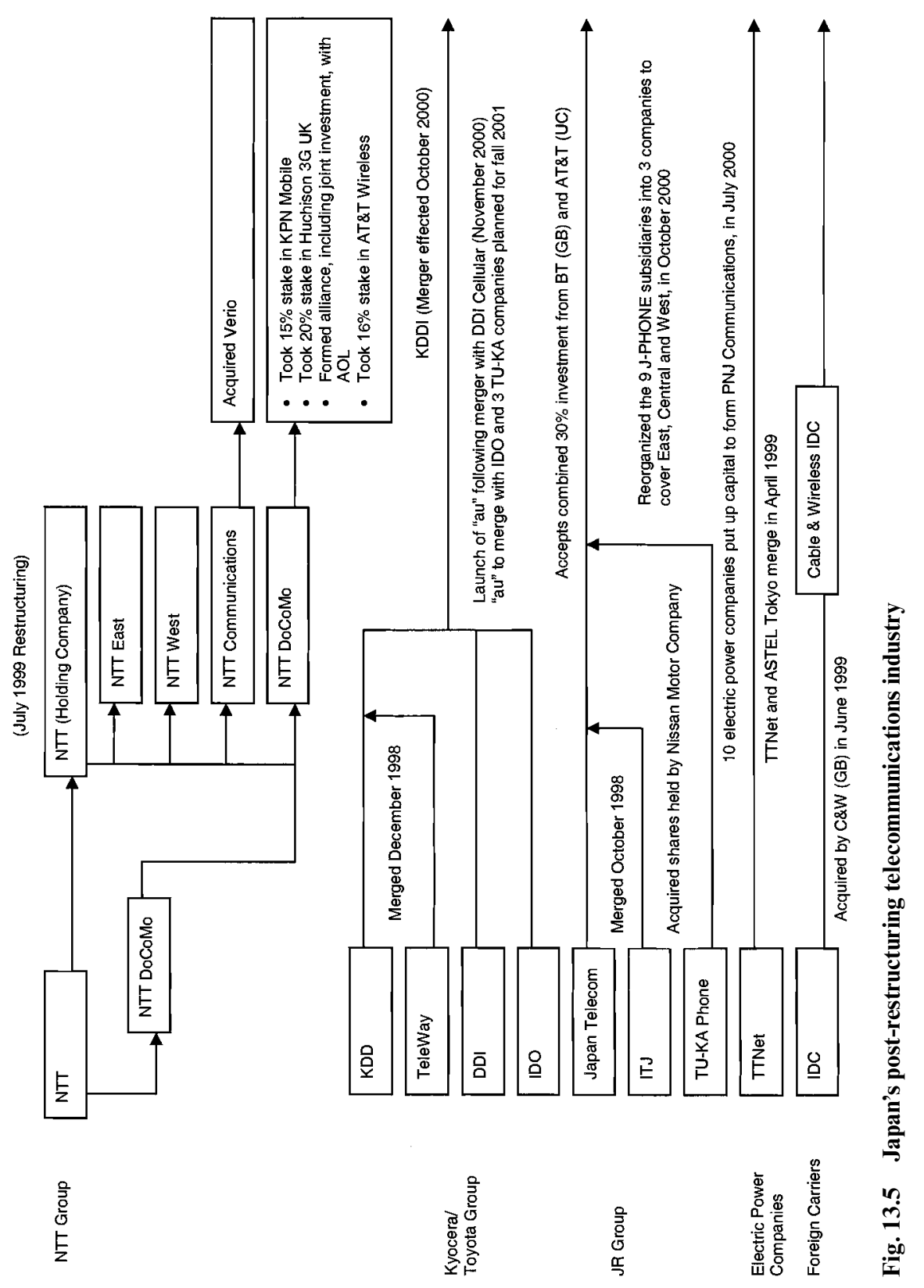


subsidiary companies in each of their franchised regions. In this sense the Japanese institutional framework seems to be progressive in developing local telephony competition, but in reality, local competition has not advanced as expected. There are several reasons for this: Local competitors have been handicapped severely because their interconnection with NTT's local network is asymmetrical. Subscribers to an electricity company's telephone network could telephone and talk to each other but NTT customers could not reach those subscribers. Local rate rebalancing did not occur and below-cost rates remained in force. This made local bypass extremely difficult compared with the United Kingdom or the United States.

In 1995 MPT finally decided to introduce the concept of the interconnection charge (at that time, it was called an access charge). Ten years had already elapsed since the NTT privatization, when the method of calculating the interconnection cost was established.

In order to enhance competition, the interconnection rate has a fundamental importance. At the same time it is quite difficult to interpret that rate in an economic sense. The difficulty comes from the fact that the majority of the embedded local interconnection costs are sunk, whereas the opportunity cost of interconnection is ever-changing because of rapid technological progress. On top of that, there usually exist huge differences in cost structure from district to district that are caused by geographical and demographic factors.

Except for the busiest business districts, the choice of local carrier is very limited. MPT decided to apply the concept of the essential facility to NTT. In each prefecture NTT was regarded as the essential facility and the interconnection rate had to be calculated according to the approved accounting rule. The rate is shown in figure 13.6.

$¥ /$ three minutes

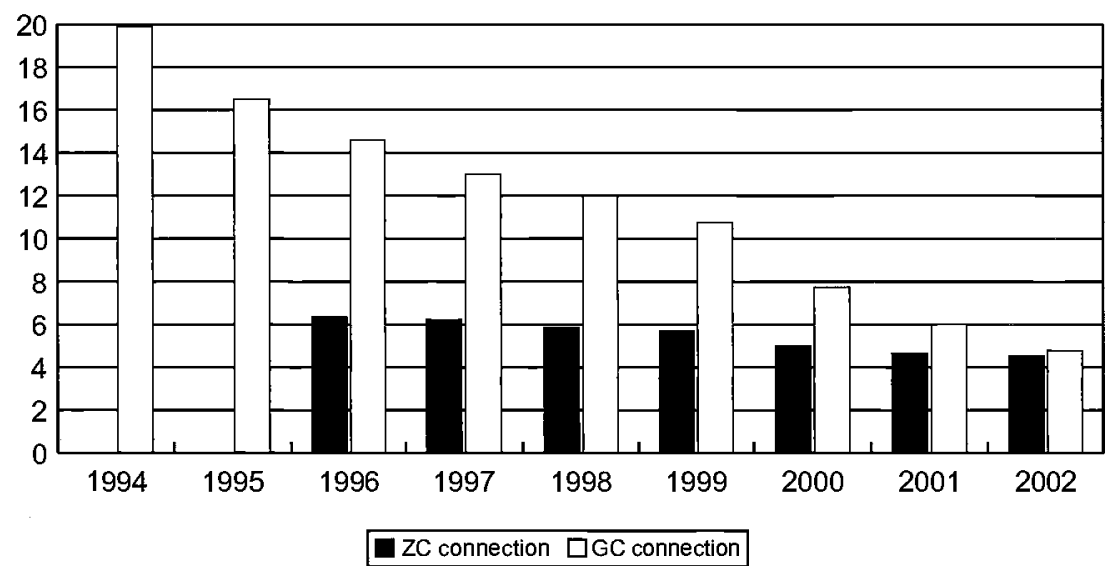

Fig. 13.6 The interconnection rate 
After the introduction of the interconnection rate, issues concerning the rate level were raised by the NCCs and the United States Trade Representative. In the United States and the United Kingdom, the concept of longrun incremental costs was introduced to calculate the interconnecting cost, because historical cost could not reflect the technological progress that had reduced the cost of local exchange drastically. On the other hand, local carriers have to suffer from the stranded costs, namely, the costs that cannot be recovered because long-run incremental costs are used to calculate the interconnection rate.

In 2000 and 2001, NTT reduced the interconnection rate drastically. The result was as expected. NTT's revenue decreased and its profits went down to their lowest level ever.

The local telephone market experienced a dramatic change in the late 1980s in the United States and the United Kingdom. Local competition was based not upon institutional niches that allowed cream skimming but on bypass technology that was developed by firms that wanted to reduce their payments to the local telephone companies. Rate rebalancing and the imposition of access charges are the most important stimuli for bypassing the local network, because they encourage competition in the local market.

The typical bypass technologies are the mobile telephone and CATV. These technologies challenge the cost structure of the incumbent's old technology. They can realize economies of scale without requiring huge numbers of customers. That is, the critical mass necessary to compete with a local telephone company is not very large.

Japan has been in a strange situation in the context of development of local competition. First, the competition between cellular technology and local telephony has not developed well simply because mobile telephone service had been too expensive. Second, competition was limited among the cellular companies that were not direct competitors to NTT's local network. Third, the regulatory scheme hampered competition once again. Wireless radio-service providers used to be defined as Type I carriers by the Telecom Business Law. As a result, MPT must regulate these carriers with regard to a tariff and to entry and exit conditions. Their rates had to be based upon accounting costs, which cannot be lowered without realizing the critical mass of subscribers. Strategic pricing to combat the local telephone network was not permitted because the requirement for financial stability as a Type I carrier was binding to avoid discontinuity of service.

\subsection{Mobile Phones}

It was not until the end of 1996 that MPT relaxed its tight policy upon the mobile industry and that industry began to explode. Under the new regime, mobile phone companies were set free to quote their prices, and fierce price competition was invited. Mobile companies were permitted to 
sell handsets and users could freely choose the style of their handsets. The development of the mobile phone industry in Japan has been characterized by the support of youngsters whose willingness to pay is much higher than that of average consumers. Mobile phones are not the usual telephones that have been regarded as a necessity, but are a kind of luxury item that can serve a large variety of optional demands, from amusements (e.g., games) to business needs. We must also note that the distinction between local and long-distance services has completely disappeared among mobile phone users. This has also happened in the case of the Internet. The development of the number of mobile subscribers is depicted in figure 13.7. The rate of growth represents demand potentials that used to be suppressed by MPT's conservative policies.

The technological advantage of wireless over wireline is obvious. It is predicted that mobile phones can convey broadband services, as well. If this prediction is valid, then the telephone industry must be structured in a manner consistent with the future direction of technology. It may also imply that the old wireline technology can survive only as a supplement to mobiles. Wireline service can be a useful vehicle for providing broadband services at low prices. In any event, wireline is a huge national asset that must be utilized wisely in the future.

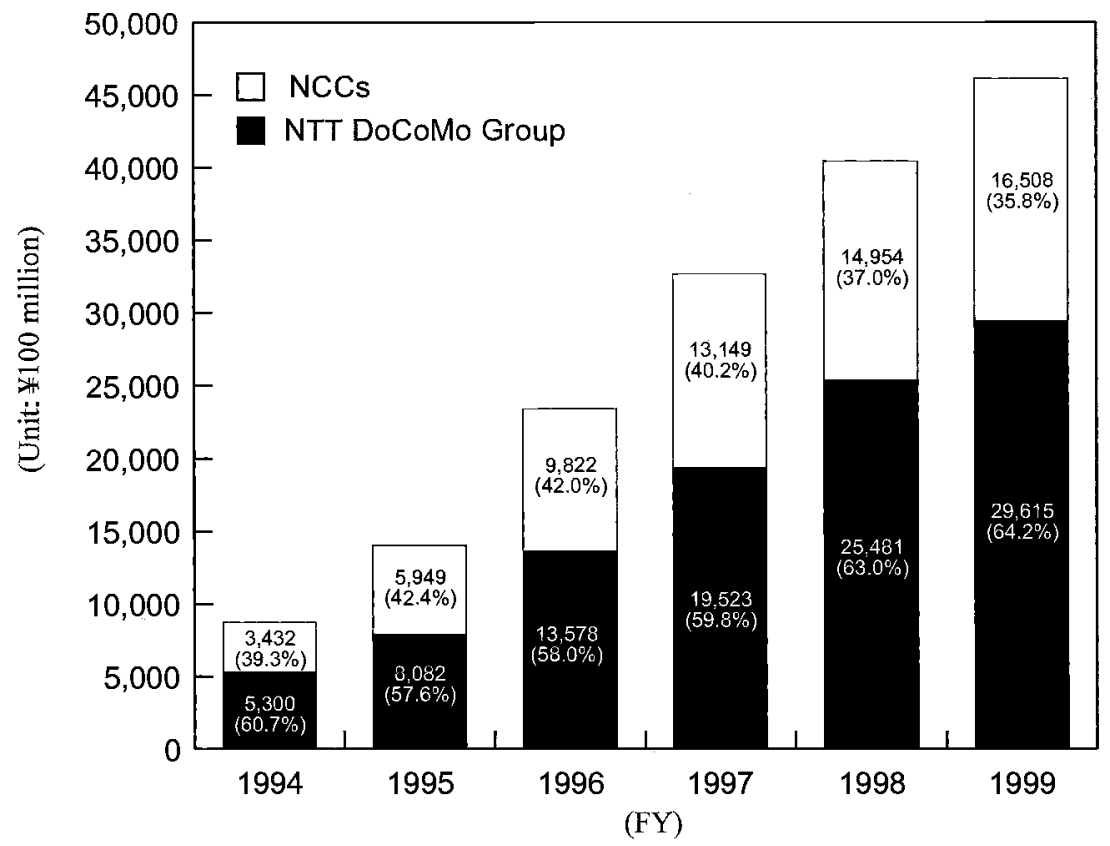

Fig. 13.7 Cellular and car phone revenues

Source: InfoCom Research, 1999 estimates. 


\subsection{Broadcasting and CATV}

The Japanese television industry consists of three types of major broadcasters: terrestrial, satellite, and CATV. The industry has been regulated by MPT. It was, and to a certain extent still is, our tradition that the administration is divided vertically into several jurisdictions. The information industry is under a dramatic structural change and the convergence of broadcasting and telecommunications is obvious. However, in the field of broadcasting there has existed a kind of ideological bias against competition: the freedom of the press, democracy, public order, and morals, to name a few examples.

The Japanese regulatory scheme has an inherent time lag but it is changing very rapidly. In this regard it is very difficult to foresee the future direction of regulation toward broadcasting. MPT is going to review the total regulatory regime for broadcasting and telecommunications. It is recognized that the present laws are preventing a smoother conversion of the two industries whereas, in reality, the NTT group is going to enter broadcasting-satellite data broadcasting and Nippon Hoso Kyokai (NHK) is planning to enter telecommunications.

In this section I describe the industrial structure of the Japanese broadcasting services and discuss the regulatory scheme, which is in transition.

\subsubsection{The Market Structure of Terrestrial Broadcasting}

Terrestrial broadcasting services have been provided by two types of entities in Japan. One is the government-owned NHK and the others are private companies. There exists competition between NHK and other private broadcasters, although the former can collect fees from the public for signal reception. The private companies depend upon advertising revenues from their television and radio shows. They are shown in table 13.1. The ratio of radio business revenue to total revenue is less than 20 percent over the past ten years.

Table 13.1

Market Share (March of each year; \%)

\begin{tabular}{lrrrrrrrrr}
\hline & 1990 & 1991 & 1992 & 1993 & 1994 & 1995 & 1996 & 1997 & 1998 \\
\hline Nippon Hoso Kyokai (NHK) & 17.6 & 20.2 & 20.7 & 21.5 & 22.6 & 22.4 & 21.6 & 20.7 & 20.6 \\
Japan News Network & 21.8 & 21.2 & 20.5 & 20.0 & 19.3 & 19.6 & 19.7 & 19.3 & 20.4 \\
Nippon News Network & 19.3 & 18.5 & 18.5 & 18.4 & 18.4 & 18.7 & 19.2 & 19.7 & 19.3 \\
Fuji News Network & 20.6 & 19.8 & 20.0 & 20.4 & 19.9 & 19.6 & 19.4 & 19.7 & 19.5 \\
All Nippon News Network & 14.9 & 14.3 & 14.1 & 13.7 & 13.6 & 13.9 & 14.1 & 14.3 & 14.0 \\
TV-Tokyo Network & 3.9 & 4.1 & 4.3 & 4.1 & 4.1 & 4.2 & 4.2 & 4.3 & 4.3 \\
Independent Broadcasters & & & & & & & & & \\
$\quad$ Association (DOKU) & 2.0 & 1.9 & 1.9 & 2.0 & 2.0 & 1.6 & 1.7 & 2.0 & 1.8 \\
Total & 100.0 & 100.0 & 100.0 & 100.0 & 100.0 & 100.0 & 100.0 & 100.0 & 100.0 \\
\hline
\end{tabular}

Source: Merrill Lynch. 
There are six private broadcasters and they own regional broadcasting stations in each prefecture. Furthermore, there exists vertical integration between the parent broadcasters in Tokyo and their regional broadcasters. The market structure of this industry is oligopolistic: NHK represents 20 percent of the industry, and the other three private companies have comparable shares.

\subsubsection{The Development of Satellite Broadcasting}

Japan has two types of satellite broadcasters; one relies on broadcasting satellite (BS) technology and the other relies on communications satellite (CS) technology. In the use of BS, Japan has been a leader and has made remarkable progress in its space CATV network. After the industry solved the technical problems of broadcasting satellite- 3 , this satellite business has been growing.

In the BS broadcasting industry, NHK is in the dominant position, followed by Japan Satellite Broadcasting, Inc., or JSB (WOWOW), as shown in table 13.2.

In contrast to BS, the growth of CS business has been slow.

PerfecTV entered the market in 1996 and merged with J Sky B in 1998 to become SkyPerfecTV. The number of subscribers is 1.73 million. DirecTV started its business in 1997 and has obtained 0.41 million subscribers thus far. DirecTV is far away from the break-even point, however. In 2000, SkyPerfecTV and DirecTV were combined to form a new company that is led by Sony and Fuji TV.

Based on the recent development of the CS broadcasting industry, MPT reportedly wants to deregulate it further. There exists regulation preventing entry by NTT and major terrestrial broadcasters, but MPT is expected to deregulate entry especially with regard to licensing the next generation of CS technology. The focus of regulation will be shifted to the oversight of the capability of program production and finance, which may give more opportunity to the NTT group.

\subsubsection{CATV Industry and Deregulation}

In 1955 CATV broadcasting started as an auxiliary device of terrestrial broadcasting in areas where radio signals are hard to reach. CATV has become a community media source since the 1970 s through the development of multichannel and two-way communications. Although the Japanese CATV industry grew steadily at the rate of 20 percent in the first half of the 1990s, its growth was not so impressive as the growth that occurred in the United States. In the latter half of the 1990s, however, there seems to have been a speeding-up of CATV development. This is due to several factors:

1. The diversification of CATV programming, made possible by the initiation of CS digital broadcast 


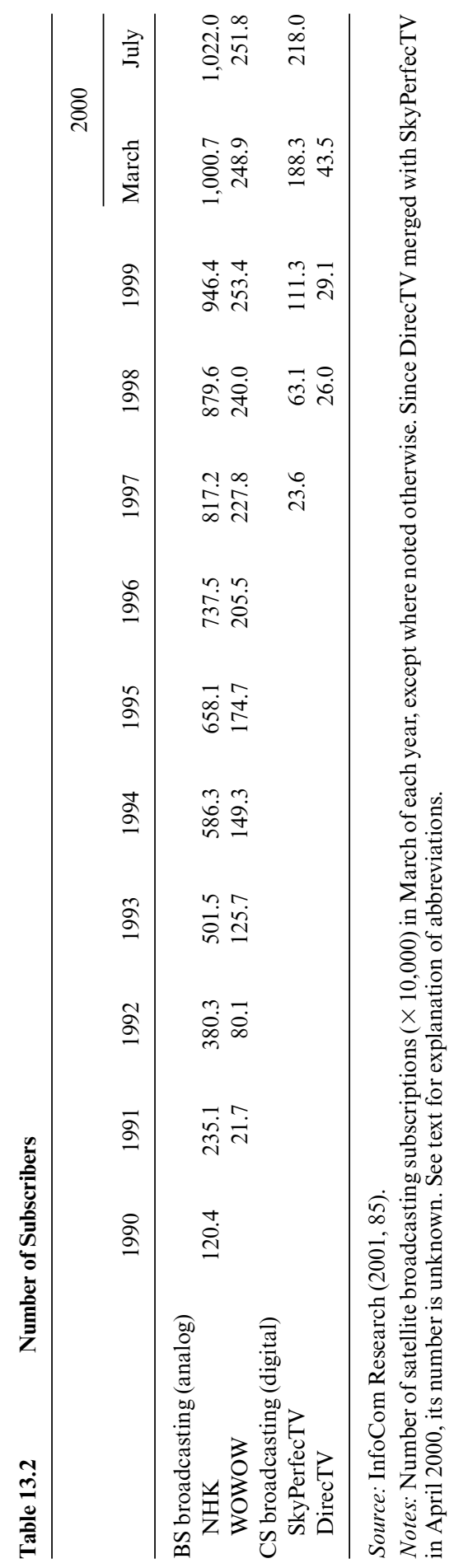


2. A deregulation policy that made it easier to open up new stations and create a multisystem operator (MSO), which is indispensable to broadcastarea expansion

3. An increase of competition among CATV companies, with a result of increased promotional activity to gain subscribers.

4. The future prospect of providing telecommunications services, especially in the application of the Internet

The effect of the change of the MPT's regulatory regime has been notable. MPT announced deregulation of the joint use of head-ends in 1997 along with abolishing the foreign capital restriction upon CATV and Type I telecom carriers. In 1998 MPT decided to simplify the authorization procedures for starting CATV operations. CATV operators that are permitted to operate as Type I telecom carriers increased dramatically. The development of CATV operators is shown in table 13.3 (parts A and B).

With the increase of full-service operators (CATV plus telecommunications), competition has been accelerated. Two examples are noteworthy in this regard. Jupiter Telecom (located at Suginami-ward) began rate cuts and large volume discounts in 1998. Titus Communications (located in Chiba city) initiated the elimination of the setup charge that used to be a barrier for new subscription. This company also introduced free night service for calls within its telecom network. Furthermore, Titus has become the first CATV operator to offer an integrated service including multichannel, telephony, and Internet services.

Looking back on the development of the CATV industry in Japan, we find several features that are not existent in the United States:

Table 13.3

CATV Operators

\begin{tabular}{|c|c|c|c|c|c|c|c|}
\hline & 1993 & 1994 & 1995 & 1996 & 1997 & 1998 & 1999 \\
\hline \multicolumn{8}{|c|}{ A. The Development of CATV Operators } \\
\hline \multirow{5}{*}{$\begin{array}{l}\text { Number of facilities } \\
\text { Number of subscribers } \\
(\times 10,000) \\
\text { Household penetration } \\
\quad \text { rate }(\%)\end{array}$} & 625 & 740 & 830 & 937 & 973 & 1,030 & 984 \\
\hline & & & & & & & \\
\hline & 242.2 & 314.3 & 363.7 & 500.1 & 672.0 & 793.6 & 947.1 \\
\hline & & & & & & & \\
\hline & 5.6 & 7.2 & 8.2 & 11.2 & 14.6 & 17.0 & 20.0 \\
\hline \multicolumn{8}{|c|}{ B. Number of CATV Operators from the Telephone Companies } \\
\hline NTT & & & & 27 & & & \\
\hline Japan Telecom & & & & 27 & & & \\
\hline KDD & & & & 5 & & & \\
\hline TTNet & & & & 5 & & & \\
\hline NTT Docomo & & & & 1 & & & \\
\hline
\end{tabular}

Source: InfoCom Research (2001).

Note: Penetration rate $=$ subscribed households/registered households. See text for explanation of abbreviations. 
1. The terrestrial broadcasting services in Japan are pervasive all through the country. The reason is a geographic difference between the United States and Japan. The United States is a fifty-state country and Japan is a one-state country. Although Tokyo and Osaka are giant cities, they are part of only one state-Japan. This is quite different from the United States. Cities such as Los Angeles, Chicago, Denver, and New York are city centers in each state. In the one-state model, like Japan, it is easier for the incumbent broadcasters to become dominant and the nationwide audience has been more attracted to the information from Tokyo. This has hampered the development of CATV as a community-based broadcaster.

2. The regulation of MPT tended to prevent entry into CATV, especially because of the stress it put upon a close connection between broadcasting and community and local content. These restraints had a negative influence on the potential profitability prospects of the CATV business.

3. Along with the regulation above, ownership of multiple CATV stations was not possible for a long time and this made it difficult for CATV operators to reach a critical mass.

\subsection{The Coincidence of Disputes over the Telecommunications Industry}

Looking around the developed countries, we notice that each of the associated telecom industries faces the same problems, that is, the delay of development of competition, especially from the viewpoint of regulators. In 1996, the Federal Communications Act of 1934 was amended with the expectation of the rapid emergence of competition between local and longdistance carriers. In 1999, NTT was restructured. A long-distance service provider was separated from local telephone companies in order to enhance competition. The results up to now, however, are rated poor by the regulators and legislators in both countries.

In the United States two things are happening at the same time. The Tauzin-Dingell bill is going to be introduced to let RBOCs invest in interLATA broadband services. This is equivalent to opening up a big hole on the 1996 act because legislators are more concerned with the development of broadband services than with the voice telephony. The Tauzin-Dingell bill appears necessary because the examples of entry by long-distance carriers into local markets and the entry of local companies into the longdistance market are scarce. This is a result of the fact that the conditions of the 1996 amendment of the communications act have rarely been met. According to the 1996 act, local carriers must satisfy almost forty checkpoints indicating that they have opened up their local markets before they are permitted to enter into long-distance markets. In typical cases, AT\&T and RBOCs do not reach an agreement easily. AT\&T argues that RBOCs are always precluding entry by failing to fulfill the checkpoints, whereas the RBOCs reply that the checkpoints are satisfied to a reasonable extent. This 
is a never-ending dispute because the game is noncooperative, with both players aiming at the lion's share of the entry benefits. The Tauzin-Dingell bill puts aside this stalemate and pushes another type of competition that looks more important for national interests.

At the same time, AT\&T has began lawsuits in several states such as Pennsylvania, New Jersey, and Florida. AT\&T claims that the structural separation of RBOCs is essential to realize fair competition in the local market. The structural separation is based on a vague distinction between wholesale and retail. However, it is noteworthy that controversy over the industrial structure of local telephony has resumed again.

The situation looks similar in Japan. Except for mobile telephones, the pace of entry into local markets seems slower than expected by regulators. The market share of NTT is 90 percent nationwide. It also is true that local competition has not occurred in every corner of the country. It has been concentrated in large cities and central business districts. This is simply because it is not profitable to enter most of Japanese local markets. Population density is low and few business centers are located in the majority of Japanese cities. This is a reflection of the geological features of Japan. But competitors of NTT never miss the opportunity to accuse NTT of an intent to prevent entry into local markets. The lack of competition in rural areas and small cities cannot be attributed to entry prevention. The news of low penetration rates in local telephony, however, gives suitable credibility to their attack on NTT.

I call this phenomenon "politicizing" entry conditions. Network industries such as telecommunications, gas, and electricity have common characteristics in that entrants rely upon a transmission mechanism that is owned by the incumbents to provide services. As a result, they have two choices. They can construct their own network if the rental prices of the transmission mechanism are higher than the cost of new investment. However, it often occurs that investment in a core network is impossible for entrants because of huge capital costs and their sunk nature. At this time there usually is a heated discussion on the appropriate rental prices for access, interconnection, and transmission or transport services.

New entrants can always benefit from arguing that the rental price imposed by the incumbent is too high to make entry profitable. If we have a neutral authority to judge the fairness of network fees, then the problem can be solved. In some cases the incumbents may be ordered to lower their prices, and in other cases entrants must pay in full the prices set by the incumbents or choose not to enter the market.

In effect, the neutral authority must have the ability to judge the efficacy of new entrants in order to prevent inefficient entry.

The solution to the problem becomes less clear when we do not have this neutral authority but instead have an inherited bureaucracy that usually intends to encourage new competition. The bureaucracy wants to be in the 
position to point to indicators of vigorous competition. The easiest way to accomplish this task is to blame the incumbent for preventing entry if expected competition does not emerge.

The risks associated with politicization lies in the fear that new entrants are permitted to survive even if they are not efficient. Inefficient entrants may not be able to pay the network fees because they do not have moreefficient equipment than the incumbents, or because they lack the knowledge to make use of the new technologies available. But politicization prevents the exposure of inefficiency. Therefore, no one knows whether the new entrants are efficient. This is not the case when politicization is absent. In this case new entrants may enter and fail because they do not have the opportunity to plea for benevolence.

In network industries the doctrine of "bottleneck" or "essential facility" has become a major source of the phenomenon of politicizing the entry conditions. ${ }^{3}$ New entrants can use the doctrine to weaken incumbents in preparation for obtaining greater market share in the future. If these entrants prove to be efficient and compete with the incumbents on an economic basis in the future, people are lucky. But if they are inefficient and collude with incumbents in the future, the result is a total loss to the country. In the name of dynamism some people argue that the expected loss is a fee for the realization of competition. This is true only if we have a fair institution that selects efficient competitions. Here we will turn to the problem of NTT restructuring.

\subsection{Future Reforms}

In Japan, as in the United States or the United Kingdom, the incumbent problem is likely to be revisited. Before arguing for another reform of the NTT group, I will point out several difficulties inherent in the present form of the restructured NTT. The reshaping of NTT in 1999 was meant to close the long-standing debate begun in 1985 regarding the necessity of breaking up NTT. The present structure of NTT is the result of a pure compromise between NTT and MPT. NTT is satisfied with the present form because it was not divided into independent companies. In theory, the NTT holding company can control their subsidiaries. MPT is satisfied because it can point to the three structurally separated companies (NTT East, NTT West, and NTT Communications) that are independent of each other.

From the viewpoint of economics, however, the new NTT has several basic difficulties. First, as was discussed, the distinction between local and long distance (and international) is nonsense. Second, neither NTT East nor NTT West can provide long-distance or interprefecture services.

3. On the economic rationale of the doctrine of "bottleneck" on "essential facility," see Nambu (1997b). 
Third, NTT Communications naturally wants to enter the local markets because the roots of business lie in the local market. The conflict of interest within one entity is damaging the efficiency of the holding company. The basic design of the system is an old paradigm of "dichotomy" that has existed since the medieval age of telecommunication.

During the process of the past reform some economists argued that NTT East and NTT West could be allowed to compete with each other. The theory underlying this argument is difficult to understand because we cannot find any incentive for two firms to squeeze into each other's market. From the viewpoint of the NTT holding company, such behavior is a zero-sum game. If NTT East and West are allowed to provide long-distance and international services as well, each would have an incentive to enter the other's market. But this is forbidden. Faced with the slowness of local telephone competition the government may find it necessary to restructure the present NTT system. At this time I must stress several points for the national interest that must not be ignored.

\subsubsection{Dividing NTT East and NTT West}

The discussion to divide NTT local companies into pieces is economically nonsense. If people think that the obstacle of entry into local markets comes from the fact that NTT East and West are monopolies, then the idea of dividing them into smaller pieces will make the matter even worse. The local companies do not have incentives to enter into a rival market if they are restricted to providing local service. In fact, smaller local companies will have ever stronger incentives to defend their markets. On top of that, some of the new local companies will face additional financial difficulty, even more so in the rural areas since they will be deprived of the capability of cross-subsidy within their territories.

\subsubsection{Risks of Mergers and Acquisitions}

No Japanese firm is free from the risk of being taken over by the current globalization of mergers and acquisitions. Looking at the share values of NTT subsidiaries, it is obvious that some firms may be acquired by foreign carriers. The idea of further dividing the NTT group will lower their share prices even more. Without an effective countermeasure for the firms in the NTT group, the risk of takeover cannot be neglected.

\subsubsection{Plural Eyes upon Wireline and Wireless}

Technological change has brought about a new era in which mobile phones play a more important role than wireline service. The advantage of wireless over wireline is obvious, but there also exists a complementary relationship between the two. The main usage of wireline will lie in a continuous, even all-day, interconnection that not possible or desirable for a wireless technology. Therefore, for a telecom enterprise both types of services 
may be economically combined. The mobile industry will continue to be competitive domestically as well as globally. NTT must be able to provide both services in order to combat global carriers.

\subsubsection{Radio Frequency}

There exists an institutional problem that needs to be solved concerning the distribution of scarce radio frequency. The United States took the approach of auctioning off radio bandwidth, which resulted in astronomically high prices. Those prices must be charged to the mobile carriers' services but it is not clear whether the mobile carriers will be able to pass these prices on to their customers. Of course, on the other hand, a rationing method overseen by the government results in an arbitrary distribution of scarce resources, which is foreign to efficiency. For the moment nothing has been made clear as to the method of apportioning radio frequency in Japan.

\section{References}

Huber, Peter W. 1987. The geodesic network. Report on competition in the telephone industry. Washington, D.C.: U.S. Department of Justice.

Huber, Peter W., Michael K. Kellogg, and John Thorne. 1992. The geodesic network II. 1993 Report on competition in the telephone industry. Washington, D.C.: The Geodesic Company.

InfoCom Research. 2001. Information and communications in Japan in 2001. Tokyo: InfoCom Research.

Nambu, Tsuruhiko. 1997a. Intervention in Japan's market for infrastructure services: Privatization without full deregulation. In EDI Learning Resources Series, Infrastructure strategies in East Asia, ed. Ashoka Mody, 97-107. Washington, D.C.: World Bank.

1997b. Is "bottleneck" a viable concept for the breakup of NTT? Telecommunications Policy 21 (2): 113-126.

\section{Comment Il Chong Nam}

Professor Nambu's paper is a very interesting and informative one both as a paper on the Japanese economy and as a paper on the telecommunications industry. A large part of his paper is devoted to the comparative analysis of the Japanese telecommunications industry and those of the United States and United Kingdom. His analysis is quite comprehensive and covers all of the important markets, including broadcasting and Internet mar-

Il Chong Nam is professor at the KDI School of Public Policy and Management, Korea Development Institute. 
kets. One can learn a lot from his paper about how the same fundamental change in technology could lead to different evolutionary paths for the same industry in different countries endowed with different infrastructures concerning the way market and government work. As an economist interested in public enterprises, I find this paper especially interesting and quite unique in that it offers a rare opportunity to take a look at how the Japanese MPT bureaucracy responded to the pressure of structural reform caused by technological innovation.

The evolution of the telecommunications industry from a government monopoly to a partially regulated competitive market involved fundamental changes in the corporate governance of former public enterprises, in the industry structure, and in the regulatory regime. It also requires that functions and authorities of the former line ministry, MPT in the case of Japan, must change substantially. Professor Nambu shows that Japan took an approach that is substantially different from those of the United States and United Kingdom on most key issues on liberalization of the telecommunications industry, such as industry structure, corporate governance of the dominant carrier, and regulation on rates and access charges.

I think the most significant difference between the path Japan took and those taken by the United States and United Kingdom lies in the corporate governance of former monopolists and in the role the government plays after liberalization. In the United States, ownership and control have always been in private hands, and regulatory functions were separate from the management of carriers. In the United Kingdom, ownership and governance of BT was handed over to private investors. Regulatory functions were also separated from the management of BT. In Japan, on the other hand, NTT is still majority owned and controlled by the government, and the regulatory regime does not appear to be independent.

I think the public nature of NTT's ownership and control lies at the core of the Japanese telecommunications industry and the policy of the Japanese government thereupon. I also think many of the differences in industry structure and regulation between the Japanese telecommunications industry and those of United States and United Kingdom, listed in Professor Nambu's paper, could be traced to NTT's ownership and control. It seems that a closer investigation of corporate governance of NTT and how it affects the policy functions of the Japanese government could lead to a better understanding of the telecommunications industry and the effectiveness of policy thereupon in Japan.

I have some specific points that I would like to take up.

I think that more detailed information on the ownership and control of NTT will be helpful. Information on actual ownership structure and the legal and policy environments surrounding the nature of government ownership in NTT will clarify the incentives of NTT managers as well as bureaucrats at MPT. 
Is NTT subject only to company laws, allowed to seek profits? Or is it subject to some laws that do not apply to the firms owned purely by private investors that make NTT's corporate governance different? Even if NTT is formally subject only to company laws, the question remains as to the nature of the government as the dominant shareholder of NTT. As the dominant shareholder, does the government concern itself only with the commercial performance of NTT or is it interested in using its control over NTT to promote some policy objectives that are not compatible with profit incentives of NTT?

Moreover, it would be interesting to ask what specific mechanisms there are for the government to resort to in trying to force NTT to perform policy functions, which could conflict with its commercial objectives. Which ministry or agency within the government exercises the share-holding right of NTT is also a relevant question because the nature of government involvement in the governance of NTT depends on it. If MPT wields the shareholding right, as it appears, it will be tempted to use its control over NTT to promote its policy objectives toward the telecommunications industry. If this happens, it will affect NTT's incentives and the degree of competition among various carriers that compete with NTT, as well as regulation.

It is also interesting to ask why Japan chose a liberalization path that allowed MPT to continue to play the potentially conflicting roles of "manager of NTT," "maker of industrial policy for the telecommunications industry," and "regulator," even though these roles conflict with each other.

I am also puzzled by the choice of the holding-company system for NTT. NTT East and NTT West are both 100 percent owned by NTT. It would not be easy to induce serious competition between two local monopolies even if they are independent firms. In the case of NTT East and NTT West, both are subsidiaries of NTT. It is not clear to me what incentives the two local monopolies have in competing with each other. If the Japanese government somehow succeeds in forcing NTT East and NTT West to actually compete with each other, there remains the question of why NTT should own NTT East and NTT West. Most major carriers around the world have been adopting holding-company structures in recent times. However, their motive was to raise internal efficiency, not to foster competition among its subsidiaries to increase social welfare.

The evolution of the telecommunications industry in Japan described by Professor Nambu raises more fundamental questions about the way economic systems evolve in different countries. The role of the state, the corporate governance of large firms, and the way the financial market is organized and functions seem to be linked closely with each other and affect the way markets and regulatory functions evolve over time. It seems that the way the market and government are organized and function in Japan makes it difficult to transform a government monopoly into a market- 
based system in which commercial operation, regulatory functions, and industrial policy objectives are separated.

My last comment is on a trend in the industry that appears irreversible. Mobile services are replacing wired services rapidly. It would be interesting to see how the mobile market has been evolving in Japan; in particular, information about the evolution of the mobile market as well as the dominant player, NTT Docomo, and its relationship with NTT would significantly enhance our understanding of the Japanese telecommunications market. Development in the third-generation market and the policy of the government toward this market also are key to understanding the future direction of the Japanese telecommunications industry.

\section{Comment Richard H. Snape}

I have enjoyed reading Professor Nambu's paper and have learned much from it. Some of the features of Japan's telecom industry are unique to Japan, but many are to be found in other countries also. These relate to problems of transition to competition in an industry in which the incumbent has been a protected, government-owned monopoly and in which there have been many cross-subsidies required by the government for political and social reasons; and in which there is very rapid technological change and convergence of technologies such that in the future there is likely to be an integrated communications, information, and entertainment medium.

There are some points which I would like to take up.

I think there could be more emphasis on the distinction between competition in facilities and in services. At this stage there is still limited competition for the copper local loop (outside central business districts). In many areas and for some services the local loop still has properties of monopoly and essential facility. While mobile phones are booming in Japan and many other countries, a high percentage of such calls still originate or terminate on copper. Outside central business districts, wireless is still not suitable for two-way broadband, and hybrid fiber coaxial (HFC) cable is generally far from ubiquitous in roll-out. So at this stage of development, access and terms of access to the local loop are still relevant for competition in services for much of the population in Japan and elsewhere. As Professor Nambu notes, this leads to the "politicization" of access-good regulation will be aimed at reducing this politicization or gaming.

Professor Nambu notes the bad relations between the incumbent and

Richard H. Snape was deputy chairman of the Productivity Commission, Australia, and emeritus professor at Monash University. He passed away in the fall of 2002. 
regulators. Of course, if this reflects ignorance on the part of the regulator, this is bad and should be remedied, though there will always be some asymmetry of knowledge. But I would expect tension between the incumbent (coming from a protected monopoly position) and a regulator trying to bring competition - indeed, I would be worried if there weren't such tension.

In a number of places the paper refers to "fairness" of prices-I would prefer a focus on efficiency of prices.

Professor Nambu very rightly refers to regulations affecting broadcasting - with convergent technologies we also need convergent regulation. In a number of countries we have policies promoting competition in telecoms, but regulations that protect incumbents in broadcasting. Such policy dissonance can only frustrate development.

The paper speaks of the risk of foreign take-overs. Already Vodafone owns a mobile phone company in Japan. I am uncertain as to what the risk is.

I note that new entrants are "selected" by MPT. Why is such selection required? Is it more selective than the "beauty contest" for the allocation of scarce spectrum undertaken in a number of other countries?

The Productivity Commission is undertaking an inquiry into telecom regulation in Australia. We are setting out some principles for regulation. They include:

- Telecom policy should aim at securing efficient outcomes rather than competition in its own right, or the protection of particular competitors.

- Social objectives are best targeted by other policy instruments or by explicit subsidies aimed at the objective.

- Policy should be technologically neutral.

- Regulation should apply only to areas where there are clearly identified problems and where regulation is an effective remedy. It should be transparent, predictable, accountable, and consistent.

- Where there are real bottlenecks justifying regulated access pricing, it is important to encourage efficiency in the use of telecom infrastructure while maintaining incentives for investment.

- Regulation should be such that the incentives for business are to make a better return from procompetitive consumer orientation, than from market foreclosure or regulatory gaming. 